\title{
Bedeutet die Zukunft der Europäischen Union das Ende unserer Verfassung
}

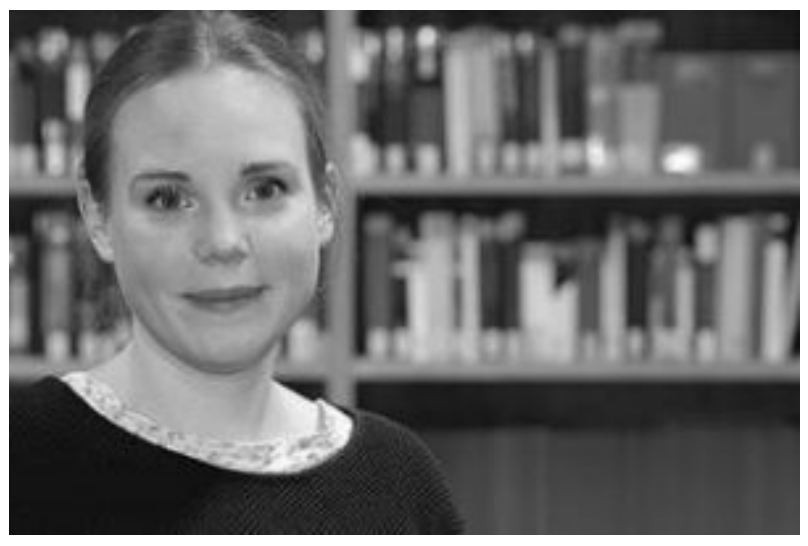

ELISABETH ROSSA

Fast zehn Jahre nach dem Inkrafttreten des Vertrages von Lissabon stellt sich mehr denn je die Frage nach der möglichen Gestalt einer zukünftigen Europäischen Union. Das gegenwärtige politische Europa scheint unter dem Eindruck wirtschaftlicher Krisen und der Herausforderungen durch den sog. Brexit den Auftrag zu einer Umgestaltung der Union erkannt und angenommen zu haben. Ausgehend von den Integrationsbestrebungen des Vertrages von Lissabon und den Reformvorschlägen der Europäischen Kommission in den fünf Kernbereichen Europäischer Zuständigkeit - der sog. europäischen Säule sozialer Rechte, der Gestaltung der Wirtschafts- und Währungsunion, der Verwirklichung von Globalisierung sowie der europäischen Verteidigungsund Finanzpolitik - können mögliche Zukunftsszenarien bewertet und deren Umsetzung auf eventuelle Fallstricke hin untersucht werden.

Ein Schwerpunkt des Vortrages liegt dabei auf der europäischen

Verteidigungspolitik. Dort ist der Reformbedarf angesichts der vielschichtigen und neuartigen Bedrohungslagen, ausgelöst beispielsweise durch Terrorismus oder Cyberangriffe, ungemein hoch und drängend. Die Vorstellungen der Europäischen Kommission reichen von Vertiefungen geringen Gewichts über eine geteilte Verantwortung unter den Mitgliedstaaten bis hin zu einer Verteidigungsunion mit weitreichender Kompetenzübertragung seitens der Vertragsstaaten an die Europäische Union. Die nationalen verfassungsrechtlichen Grenzen einer Übertragung von Hoheitsrechten sind insbesondere dem Lissabon-Urteil des Bundesverfassungsgerichts aus dem Jahr 2009 zu entnehmen. Auch wenn die konkrete Reichweite der zu schützenden „Verfassungsidentität“ unter Wahrung des Demokratie- und Subsidiaritätsprinzips nur im Einzelfall zu bestimmen ist, so lassen sich doch vermeintlich verallgemeinerungsfähige Grenzen für die europäische Verteidigungsarchitektur diskutieren. Dabei sind nicht nur Einsätze deutscher Streitkräfte im Ausland anzusprechen, sondern 
auch die verfassungsrechtliche Anknüpfungsnorm einer Verteidigungsunion oder eines europäischen Verteidigungsfonds zur Finanzierung von Forschung und Rüstungsbestrebungen. Auf vorrangig politischer Ebene sind zudem die Auswirkungen einer Stärkung des europäischen Verteidigungssystems im Zusammenhang mit der NATO zu beleuchten.

Sollte ein von der Europäischen Union gewünschter Integrationsschritt die verfassungsrechtlichen Grenzen überschreiten, sich aber dennoch aus Sicht der Mitgliedstaaten als politisch opportun erweisen, ergibt sich unweigerlich das Problem des verfassungsrechtlich gebotenen Vorgehens. Da ein Verlassen der Europäischen Union in diesem Fall politisch keine Option darstellen soll, bleibt nur die Möglichkeit einer Anpassung des die Integration beschränkenden Grundgesetzes. Ob dies „nur“ eine Verfassungsänderung meint oder gar die Notwendigkeit einer Verfassungsneugebung, ist umstritten. Überwiegend wird man aber annehmen können, dass eine neue Verfassung nach Maßgabe des Art. 146 GG das verfassungsrechtliche Mittel der Wahl wäre. Dass dieser Weg mit vielen Unwägbarkeiten verbunden ist, zumal es sich dabei um verfassungsrechtliches Neuland handelt, erschließt sich unmittelbar. Dennoch scheint diese Variante angesichts der zu einer maßgeblichen Vertiefung der Integration notwendigen Kompetenzübertragungen nicht fernliegend. Ob dies allerdings auch für den Bereich der europäischen Verteidigungspolitik gilt, ist noch zu erörtern - ebenso wie die Frage, ob sich die Zukunft der Europäischen Union eher in vielen kleinen (Integrations-)Schritten verwirklicht oder ob es eines grundsätzlich neuen Vertrages unter den Mitgliedstaaten bedarf.

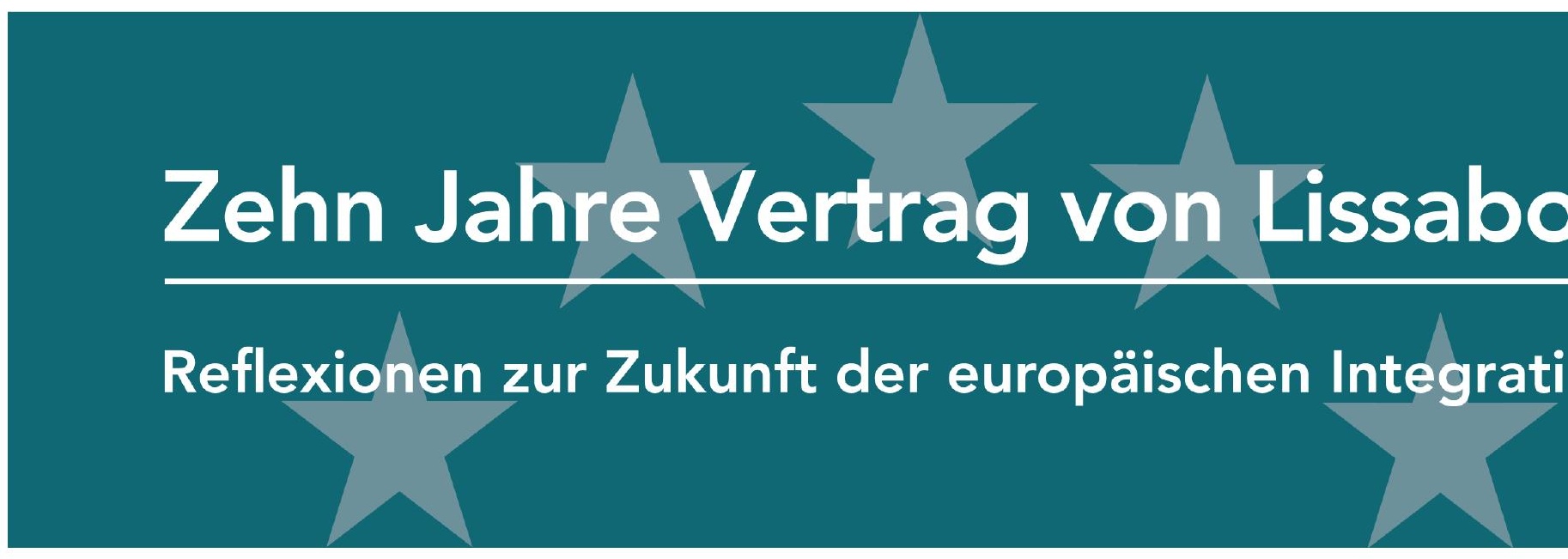

Zitiervorschlag: Elisabeth Rossa, Bedeutet die Zukunft der Europäischen Union das Ende unserer Verfassung, JuWissBlog Nr. 72/2019 v. 20.6.2019, https:// www.juwiss.de/72-2019/

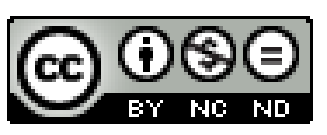

Dieses Werk ist lizenziert unter einer Creative Commons Namensnennung - Nicht kommerziell - Keine Bearbeitungen 4.0 International Lizenz. 
(cc) EY-NC-ND

- 3 - 